Original Article (short paper)

\title{
A detailed comparison of oxygen uptake kinetics at a range of exercise intensities
}

\author{
Cain C. T. Clark $^{1,2}$, Stephen B. Draper ${ }^{1}(\mathbb{0}$ \\ ${ }^{1}$ Hartpury University, Applied Sport Science, Gloucestershire, GL10 3BE, UK; \\ ${ }^{2}$ Faculty of Health and Life Sciences, Coventry University, Coventry, CVI 5FB, UK.
}

\begin{abstract}
Aim: The aim of this study was to comprehensively examine oxygen uptake $\left(\mathrm{V}_{2}\right)$ kinetics during cycling through mathematical modeling of the breath-by-breath gas exchange responses across eight conditions of unloaded cycling to moderate to high-intensity exercise. Methods: Following determination of GET and $\dot{\mathrm{VO}}_{2 \text { peak }}$, eight participants (age: $24 \pm 8 \mathrm{y}$; height: $1.78 \pm 0.09 \mathrm{~m}$; mass: $76.5 \pm 10.1 \mathrm{~kg} ; \dot{\mathrm{V}}_{2 \text { peak }}: 3.89 \pm 0.72 \mathrm{Lmin}^{-1}$ ) completed a series of square-wave rest-to-exercise transitions at; $-20 \% \Delta$ (GET minus $20 \%$ of the difference in $\mathrm{V}_{2}$ between that at GET and $\mathrm{VO}_{2 \text { peak }}$ ), $-10 \% \Delta$, GET, $10 \% \Delta, 20 \% \Delta, 30 \% \Delta, 40 \% \Delta$, and $50 \% \Delta$. The $\dot{\mathrm{VO}}_{2}$ kinetic response was modelled using mono- and bi-exponential non-linear regression techniques. The difference in the standard error of the estimates (SEE) for the mono- and bi-exponential models, and the slope of $\mathrm{V}_{2}$ vs time (for the final minute of exercise) were analysed using paired and one-sample t-tests, respectively. Results: The bi-exponential model SEE was lower than the monoexponential model across all exercise intensities $(\mathrm{p}<0.05)$, indicating a better model fit. Steady-state $\dot{\mathrm{V}}_{2}$ was achieved across all exercise intensities (all $\dot{\mathrm{V}} \mathrm{O}_{2}$ vs. time slopes; $\mathrm{p}>0.05$ ). The modelled slow component time constants, typical of literature reported values, indicated that the $\dot{\mathrm{V}} \mathrm{O}_{2}$ kinetic response would not be completed during the duration of the exercise. Conclusion: It was shown that the addition of the more complex bi-exponential model resulted in a better model fit across all intensities (notably including sub-GET intensities). The slow component phase was incomplete in all cases, even when the investigation of slopes indicated that a steady state had been achieved.
\end{abstract}

Keywords: exercise physiology; oxygen uptake; gas exchange; model; cycling.

\section{Introduction}

Oxygen uptake $\left(\dot{\mathrm{V}}_{2}\right)$ kinetics refers to the gas exchange responses to the on-or-offset of exercise ${ }^{1,2}$ and have been shown to respond differently above and below the gas exchange threshold (GET) ${ }^{3-5}$. The conventional measure of GET has been defined as the breakpoint in the slope of the relationship between $\mathrm{CO}_{2}$ output and $\mathrm{O}_{2}$ uptake ${ }^{6,7}$. It has been shown in constant work rate exercise, below the GET, that $\dot{\mathrm{VO}}_{2}$ increases in mono-exponential fashion, attaining steady-state within $\sim 3 \mathrm{~min}$ ${ }^{3,4}$. For exercise intensities that are above GET, $\dot{\mathrm{VO}}_{2}$ is widely reported to no longer increase in a simple mono-exponential manner due to a delayed response termed the slow component of $\dot{\mathrm{V}}{ }_{2}{ }^{8,9}$. The slow component has been described as a continued rise in $\dot{\mathrm{V}}_{2}$ beyond the third minute of exercise (for intensities above GET) ${ }^{5}$; this is further characterised as a delayed response becoming superimposed on the exponential rise in $\dot{\mathrm{VO}}_{2}$ at the onset of exercise ${ }^{10}$.

The time course of an exponential process is characterised by the time constant $(\tau)$ and must be complete after $5 \mathrm{x} \tau$ has elapsed ${ }^{11}$. However, reported slow component magnitudes for steady-state supra-GET intensity exercise demonstrated an issue of disparity, as most studies that elicit supra-GET intensity exercise have reported values for $1 \tau$ the $\dot{\mathrm{V}} \mathrm{O}_{2}$ response would not be complete within the exercise bout. Therefore, the reliability of the physiological inferences made, based on this model, are questionable ${ }^{12}$. The widespread inferences made from the aforementioned exponential model are evident in the literature (see ${ }^{13-19}$ ), and although only an estimate, none of the $\dot{\mathrm{V}} \mathrm{O}_{2}$ responses would be complete within $5 \times \tau$, thereby questioning the veracity and suitability of current modelling procedures to adequately describe the $\dot{\mathrm{VO}}_{2}$ response.

Across all literature in the supra-GET intensity domain, we cannot find an instance where the exercise duration was sufficient to allow the full emergence a slow component (as described by the slow component $\tau$; typically only $1 \tau$ has elapsed), therefore, the aim of this study was to comprehensively examine oxygen uptake $\left(\dot{\mathrm{V}}_{2}\right)$ kinetics during cycling through mathematical modeling of the breath-by-breath gas exchange responses at a range of exercise intensities.

\section{Materials and method}

\section{Participants and settings}

Eight male volunteers agreed to take part in the present study (mean \pm SD; Age $24 \pm 8 \mathrm{y}$, Height $1.78 \pm 0.09 \mathrm{~m}$, Mass $76.7 \pm 10.1 \mathrm{~kg}$, $\dot{\mathrm{V}} \mathrm{O}_{2 \text { peak }} 3.89 \pm 0.72{\mathrm{~L} \cdot \mathrm{min}^{-1}, \dot{\mathrm{VO}}}_{2}$ at GET $2.16 \pm 0.49 \mathrm{~L}^{\mathrm{min}}{ }^{-1}$ ). Each subject was familiar with a laboratory setting and exercise protocols. Participants were instructed to arrive at the laboratory for testing rested, hydrated, having refrained from alcohol and caffeine intake 24 and 6 hours respectively prior to testing, 
a minimum of 3 hours post-prandial and to have avoided maximal intensity exercise 48 hours preceding a test session. Tests were administered at the same time of day ( \pm 2 hours) for each participant to minimise the effect of diurnal variation on results ${ }^{20}$. This study was approved by the institutional Research Ethics Sub-Committee (REC:12/0903091) and conformed to the Declaration of Helsinki.

\section{Instruments and procedures}

The participants were required to visit the laboratory on nine occasions for testing. The first visit involved determination of GET and $\dot{\mathrm{V}} \mathrm{O}_{2 \text { peak }}$ with a progressive ramp exercise test. The following tests involved multiple laboratory visits, where participants performed a square-wave transition from seated rest to unloaded cycling, to one of eight exercise intensities; $-20 \% \Delta$ (GET minus $20 \%$ of the difference in $\dot{\mathrm{VO}}_{2}$ between that at GET and $\mathrm{VO}_{2 \text { peak }}$ ), $-10 \% \Delta$, GET, $10 \% \Delta, 20 \% \Delta, 30 \% \Delta, 40 \% \Delta$ and $50 \% \Delta$. No more than two transitions were completed in 1 day, with at least one-hour recovery between transitions. The square-wave transitions were performed in a counterbalanced design using an 8x8 Latin square algorithm ${ }^{21}$.

All tests were performed on an electromagnetically braked cycle ergometer (Lode, Excalibur Sport, Groningen, The Netherlands). The horizontal and vertical adjustments of the handlebars and saddle were measured using a tape measure and recorded and reproduced for all subsequent tests. Participants were instructed to cycle at a self-selected cadence and were encouraged to maintain this cadence throughout the entire test. If the self-selected cadence fell by more than $5 \mathrm{rev} \cdot \mathrm{min}^{-1}$, verbal encouragement was given.

Throughout each test, and following standardised measurement of atmospheric pressure, the participants breathed through a low dead-space $(90 \mathrm{ml})$, low resistance $\left(5.5 \mathrm{~cm} \mathrm{H}_{2} \mathrm{O}\right.$

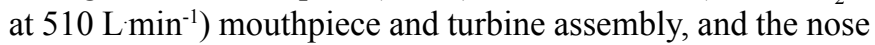
was occluded using a nose clip. Gases were drawn continuously from the mouthpiece through a $2 \mathrm{~m}$ sampling line $(0.5 \mathrm{~mm}$ internal diameter) to a mass spectrometer (Pulmolab EX671, Ferraris, Rainham, UK) where they were analysed for $\mathrm{O}_{2}, \mathrm{CO}_{2}$, and $\mathrm{N}_{2}$ (with a 200ms delay). Expired volumes were determined using a turbine volume transducer (Interface Associates, Alifovieja, US). The mass spectrometer was calibrated before each test using gas mixtures (Linde Gas, London, UK) for which the concentrations of $\mathrm{O}_{2}, \mathrm{CO}_{2}$ and $\mathrm{N}_{2}$ were known. The turbine was calibrated before each test using a $3 \mathrm{~L}$ calibration syringe (Hans Rudolf, Kansas, US). Oxygen uptake was calculated and displayed on a breath-by-breath basis. The volume and concentration signals were integrated by computer, following analogue-to-digital conversion, with account taken of the gas transit delay through the capillary and room temperature (which was maintained at $21^{\circ} \mathrm{C}$ ).

Capillary blood samples $(5 \mu \mathrm{L})$ were drawn from the fingertip and assayed for lactate concentration using a single use test strip and an automated analyser (Lactate Pro, Arkay Inc., Kyoto, Japan). Body mass was determined using a calibrated set of digital scales (Seca, Birmingham, UK) and recorded to the nearest $0.1 \mathrm{~kg}$. Height was measured using a wall-mounted stadiometer (Holtain Ltd., Crymych, UK) and recorded to the nearest $0.01 \mathrm{~m}$.

The participants performed a progressive ramp exercise test to volitional exhaustion in order determine GET and $\dot{\mathrm{VO}}_{2 \text { peak }}$. During the progressive ramp test, the first two minutes were set at $0 \mathrm{~W}$ to allow respiratory data to stabilise. The ramp rate was set at $20 \mathrm{~W} \cdot \mathrm{min}^{-1}$, commencing at $60 \mathrm{~W}$ (altered dependent upon fitness level of individual to elicit exhaustion in approximately $12 \mathrm{~min}$ ). Volitional exhaustion was determined when the participant could not maintain a self-selected cadence, after three verbal encouragements. At test cessation, a five-minute recovery period at a power output of $50 \mathrm{~W}$ commenced.

Gas exchange threshold was identified using the V-slope method ${ }^{6}$. This method consisted of plotting $\mathrm{CO}_{2}$ production over $\mathrm{O}_{2}$ utilization and identifying a breakpoint in the slope of the relationship between these two variables. The level of exercise intensity corresponding to this breakpoint was considered the GET ${ }^{6}$. In instances GET could not be identified using the V-slope method, the ventilatory equivalent method was used; which identified the oxygen uptake which caused the first rise in the ventilatory equivalent of oxygen $\left(\dot{\mathrm{V}}_{\mathrm{E}} / \dot{\mathrm{V}}_{2}\right)$ without a simultaneous rise in the ventilatory equivalent of carbon dioxide $\left(\dot{\mathrm{V}}_{\mathrm{E}} / \dot{\mathrm{VCO}}_{2}\right)^{7}$.

Extrapolation of the relationship between $\dot{\mathrm{VO}}_{2}$ and power $(\mathrm{W})$ from the progressive ramp exercise test was used to calculate the power-requiring; $-20 \% \Delta,-10 \% \Delta$, GET, $10 \% \Delta, 20 \% \Delta, 30 \% \Delta$, $40 \% \Delta$ and $50 \% \Delta$. Subsequently, participants performed a series of square wave transitions of eight minutes in duration at the eight exercise intensities on separate days. The exercise protocol began with subjects sitting on the cycle ergometer for five minutes, followed by two minutes unloaded $(0 \mathrm{~W})$ cycling, followed by the load being applied to attain the desired Watts for each exercise bout. Participants cycled at a self-selected cadence and this was reproduced for all tests. Fingertip capillary blood samples were drawn and assayed immediately pre and one-minute post the eight-minute exercise period. The difference between the end exercise $\left[\mathrm{La}^{-1}\right]$ and the resting $\left[\mathrm{La}^{-1}\right]$ was expressed as a delta value $\left(\Delta\left[\mathrm{La}^{-1}\right]\right)$.

\section{Data analysis}

Respiratory data were calculated and displayed on a breathby-breath basis. Graphical plots of the ventilatory equivalents $\left(\dot{\mathrm{V}}_{\mathrm{E}} / \dot{\mathrm{VO}}_{2}\right.$ and $\dot{\mathrm{V}}_{\mathrm{E}} / \dot{\mathrm{VCO}}_{2}$ ) were plotted to allow identification, using a least squares approach, and removal of data past the respiratory compensation point $(\mathrm{RCP})^{22}$. For all tests, breathby-breath data had any values that were three or more standard error of the estimate (SEE) removed ${ }^{23}$.Non-linear least squares regression techniques were used to fit the square-wave data after the onset of exercise with an exponential function. An iterative process ensured the sum of squared error was minimised. The mathematical models used were unconstrained and are detailed below (equation $1^{3}$ and equation $2{ }^{10}$ ). In accordance with ${ }^{23}$, the cardio-dynamic phase (the first 15-s) was removed prior to modelling. 


$$
\dot{V} O_{2}(t)=A_{0}+A_{1}\left(1-e^{-\left(t-\delta_{l} / \tau_{l}\right)}\right.
$$

Equation 1. Mono-exponential model.

$$
\dot{V} O_{2}(t)=A_{0}+A_{1}\left(1-e^{-\left(t-\delta_{1} / \tau_{1}\right)}+A_{2}\left(1-e^{-\left(t-\delta_{2} / \tau_{2}\right)}\right.\right.
$$

Equation 2. Bi-exponential model.

Where $A_{0}$ is the resting baseline value, $A_{1}$ and $A_{2}$ are the amplitudes for the two components, $\tau_{1}$ and $\tau_{2}$ are the time constants for the two components, and $t-\delta_{1}$ and $t-\delta_{2}$ are the time delays from the onset of exercise for the two components. Residual data for both model fits was also reported.

The Standard Error of the Estimate (SEE) for both mono and bi exponential models (Equation 3 and 4, respectively) was calculated using the following process;

$$
\text { SEEmono }=\sqrt{\left(\frac{S S E}{N C A S E S-3}\right)}
$$

Equation 3. Standard error of the estimate for mono-exponential modelling.

$$
S E E b i=\sqrt{\left(\frac{S S E}{N C A S E S-6}\right)}
$$

Equation 4. Standard error of the estimate for bi-exponential modelling.

Where SEEmono is the standard error of the estimate for the mono-exponential model, SEEbi is the standard error of the estimate for the bi-exponential model, SSE is the sum of squared errors and NCASES are the number of data sets (three in mono-exponential: $\mathrm{A}_{1}, \delta_{1}$ and $\tau_{1}$. Six in bi-exponential: $\mathrm{A}_{1}, \delta_{1}, \tau_{1}, \mathrm{~A}_{2}, \delta_{2}$ and $\left.\tau_{2}\right)$.

\section{Statistical analysis}

All statistical analyses were performed using IBM Statistical Package for the Social Sciences (SPSS) for Windows (Version 24.0). The difference in the SEE for the mono- and bi-exponential models, and the slope of $\dot{\mathrm{VO}}_{2}$ vs time (for the final minute of exercise), were analysed using paired and onesample $t$-tests, respectively. The data were reported as mean \pm SD unless otherwise stated. The alpha level was set equal to 0.05 , a priori.

\section{Results}

The modelled parameters from both models are contained in Table 1, together with the evaluation of the goodness of fit (SEE). This demonstrated that the bi-exponential model apparently fits better $(p<0.05)$ at all exercise intensities including those at or below GET (moderate).

The $\dot{\mathrm{VO}}_{2}$ vs time slope analyses are displayed in Table 1, highlighting that a steady-state $\dot{\mathrm{V}} \mathrm{O}_{2}$ was achieved $(p<0.05)$ at all exercise intensities including those at or below GET. Contradictorily, the mathematically modelled parameters (slow component time constant), which were typical of literature reported values, indicated that the full $\dot{\mathrm{VO}}_{2}$ kinetic response would not be achieved within the duration of the ascribed exercise bouts (Table 1).

Table 2 displays the average blood Lactate responses as a function of exercise intensity, and demonstrates that there was no significant change in blood Lactate concentration sub-GET from pre-exercise values, with significant changes only being noted in supra-GET exercise intensities (Table 2). The $\dot{\mathrm{VO}}$ kinetic response of a typical participant to the eight different

\begin{tabular}{|c|c|c|c|c|c|c|c|c|}
\hline Variable & $-20 \% \Delta$ & $-10 \% \Delta$ & GET & $+10 \% \Delta$ & $+20 \% \Delta$ & $+30 \% \Delta$ & $+40 \% \Delta$ & $+50 \% \Delta$ \\
\hline \multicolumn{9}{|c|}{ Mono-exponential } \\
\hline $\begin{array}{l}\text { Baseline } \\
\left(\mathrm{ml} \cdot \mathrm{min}^{-1}\right)\end{array}$ & 737 (247) & $630(200)$ & $680(335)$ & $620(302)$ & $617(334)$ & 737 (219) & $800(353)$ & $758(236)$ \\
\hline $\mathrm{A}_{1}\left(\mathrm{ml} \mathrm{min}^{-1}\right)$ & $1329(387)$ & $1568(476)$ & $1644(474)$ & $1803(569)$ & 2101584 & $2139(418)$ & $2232(513)$ & $2592(525)$ \\
\hline$\delta_{1}(\mathrm{~s})$ & $12.3(8.1)$ & $8.3(4.9)$ & $9.1(5.4)$ & $8.3(5.4)$ & $8.1(3.7)$ & $9.1(7.4)$ & $9.7(7.1)$ & $13.9(12.9)$ \\
\hline$\tau_{1}(\mathrm{~s})$ & $26.9(13.3)$ & $29.8(14.8)$ & $25.9(6.5)$ & $29.5(9.1)$ & $38.5(13.4)$ & $39.9(11.2)$ & $42(3.6)$ & $44.3(10.1)$ \\
\hline $\begin{array}{l}\text { Gain } \\
\left(\mathrm{ml} \cdot \min \cdot \mathrm{W}^{-1}\right)\end{array}$ & $8(1)$ & $9(2)$ & $9(1)$ & $9(2)$ & $9(2)$ & $9(2)$ & $9(2)$ & $10(1)$ \\
\hline \multicolumn{9}{|c|}{ Bi-exponential } \\
\hline $\begin{array}{l}\text { Baseline } \\
\left(\mathrm{ml} \cdot \mathrm{min}^{-1}\right)\end{array}$ & 737 (247) & $630(200)$ & $680(335)$ & $620(302)$ & $617(334)$ & 737 (219) & $800(353)$ & $758(236)$ \\
\hline $\mathrm{A}_{1}\left(\mathrm{ml} \mathrm{min}^{-1}\right)$ & $1218(334)$ & $1410(369)$ & $1541(410)$ & $1659(556)$ & $1903(554)$ & $1876(478)$ & $2004(505)$ & 2092 (499) \\
\hline$\delta_{1}(\mathrm{~s})$ & $15.7(9.91)$ & $14.4(7.39)$ & $12.5(7.08)$ & $12.7(5.43)$ & $11.5(2.02)$ & $12.6(4.17)$ & $12.1(3.4)$ & $10.5(4.05)$ \\
\hline$\tau_{1}(\mathrm{~s})$ & $23.3(12.1)$ & $25.6(4.95)$ & $27.7(8.2)$ & $25.9(8.9)$ & $27.1(4.34)$ & $28.2(5.22)$ & $28.8(8.3)$ & $29.4(13.8)$ \\
\hline $\mathrm{A}_{2}\left(\mathrm{ml} \mathrm{min}^{-1}\right)$ & $123(121)$ & $227(151)$ & $274(135)$ & $280(165)$ & $315(121)$ & 417 (115) & 437 (149) & $597(344)$ \\
\hline$\delta_{1}(\mathrm{~s})$ & $110(67)$ & $165(81.3)$ & $166(111)$ & $161(56)$ & 148 (29.9) & $148(52.8)$ & $131(47.5)$ & $137(53.9)$ \\
\hline$\tau_{1}(\mathrm{~s})$ & $240(331)$ & $155(167)$ & $171(121)$ & $121(136)$ & $125(103)$ & $239(355)$ & $146(110)$ & $187(170)$ \\
\hline $\begin{array}{l}\text { Gain } \\
\left(\mathrm{ml} \cdot \min \cdot \mathrm{W}^{-1}\right)\end{array}$ & $9(1)$ & $10(2)$ & $10(2)$ & $10(1)$ & $11(2)$ & $11(2)$ & $11(2)$ & $12(2)$ \\
\hline
\end{tabular}
exercise intensities is represented in Figure 1.

Table 1. Parameters of the oxygen uptake response as a function of exercise intensity for the mono- and bi-exponential model, $\dot{V}_{2}$ vs time slopes and standard error of the estimates. 
Table 1. Continued

\begin{tabular}{|c|c|c|c|c|c|c|c|c|}
\hline Variable & $-20 \% \Delta$ & $-10 \% \Delta$ & GET & $+10 \% \Delta$ & $+20 \% \Delta$ & $+\mathbf{3 0 \%} \%$ & $+40 \% \Delta$ & $+50 \% \Delta$ \\
\hline \multicolumn{9}{|c|}{$\dot{\mathrm{VO}}_{2}$ vs time slopes } \\
\hline $\begin{array}{l}\text { Mean slope } \\
\left(\mathrm{ml} \cdot \mathrm{min}^{-1} \mathrm{~s}^{-1}\right)\end{array}$ & $0.398(1.666)$ & $-0.363(1.289)$ & $0.268(1.551)$ & $1.208(1.937)$ & $1.108(0.993)$ & $0.393(1.329)$ & $0.770(1.669)$ & $2.293(4.465)$ \\
\hline$p$ Value & 0.521 & 0.453 & 0.641 & 0.121 & 0.160 & 0.431 & 0.233 & 0.189 \\
\hline \multicolumn{9}{|c|}{ Standard error of the estimates } \\
\hline Mono & $0.179(0.058)$ & $0.199(0.049)$ & $0.206(0.058)$ & $0.214(0.066)$ & $0.243(0.078)$ & $0.254(0.086)$ & $0.271(0.090)$ & $0.287(0.121)$ \\
\hline $\mathrm{Bi}$ & $0.173(0.053)$ & $0.186(0.042)$ & $0.194(0.055)$ & $0.201(0.061)$ & $0.226(0.066)$ & $0.238(0.078)$ & $0.259(0.087)$ & $0.271(0.121)$ \\
\hline$p$ Value & $0.02 *$ & $0.01^{*}$ & $0.029 *$ & $0.003 *$ & $0.03 *$ & $0.02 *$ & $<0.001^{*}$ & $0.009 *$ \\
\hline
\end{tabular}

$\mathrm{A}_{1}$ Primary amplitude, $\delta_{1}$ Time delay for the primary amplitude, $\mathrm{A}_{2}$ Slow component $\delta_{2}$ Time delay for the slow component, $\tau_{2}$ Time constant for the slow component. Values are presented as the mean (SD). * denotes significant difference. $(p<0.05)$.

Table. 2. Average blood lactate responses as a function of exercise intensity.

\begin{tabular}{|c|c|c|c|c|c|c|c|c|}
\hline Variable & $-20 \% \Delta$ & $-10 \% \Delta$ & GET & $+10 \% \Delta$ & $+20 \% \Delta$ & $+30 \% \Delta$ & $+40 \% \Delta$ & $+50 \% \Delta$ \\
\hline Pre Exercise $\left[\mathrm{La}^{-}\right]\left(\mathrm{mMol}^{-1}\right)$ & $1.22(0.15)$ & $1.23(0.25)$ & $1.17(0.18)$ & $1.13(0.17)$ & $1.12(0.14)$ & $1.16(0.17)$ & $1.2(0.16)$ & $1.07(0.16)$ \\
\hline Post Exercise $\left[\mathrm{La}^{-}\right]\left(\mathrm{mMol}^{-1}\right)$ & $1.23(0.25)$ & $1.26(0.29)$ & $1.6(0.21)$ & $2.42(0.26)$ & $2.98(0.22)$ & $3.97(0.62)$ & $4.55(0.47)$ & $5.93(0.37)$ \\
\hline Delta $\left[\mathrm{La}^{-}\right]\left(\mathrm{mMol}^{-1}\right)$ & $0.01(0.11)$ & $0.03(0.08)$ & $0.43(0.1)$ & $1.29(0.16)$ & $1.86(0.25)$ & $2.81(0.6)$ & $3.35(0.39)$ & $4.86(0.38)$ \\
\hline$p$ Value & 0.763 & 0.451 & $<0.001 *$ & $<0.001^{*}$ & $<0.001 *$ & $<0.001^{*}$ & $<0.001 *$ & $<0.001^{*}$ \\
\hline
\end{tabular}

Values are presented as the mean (SD).

$*$ denotes significant difference $\mathrm{p}<0.05$
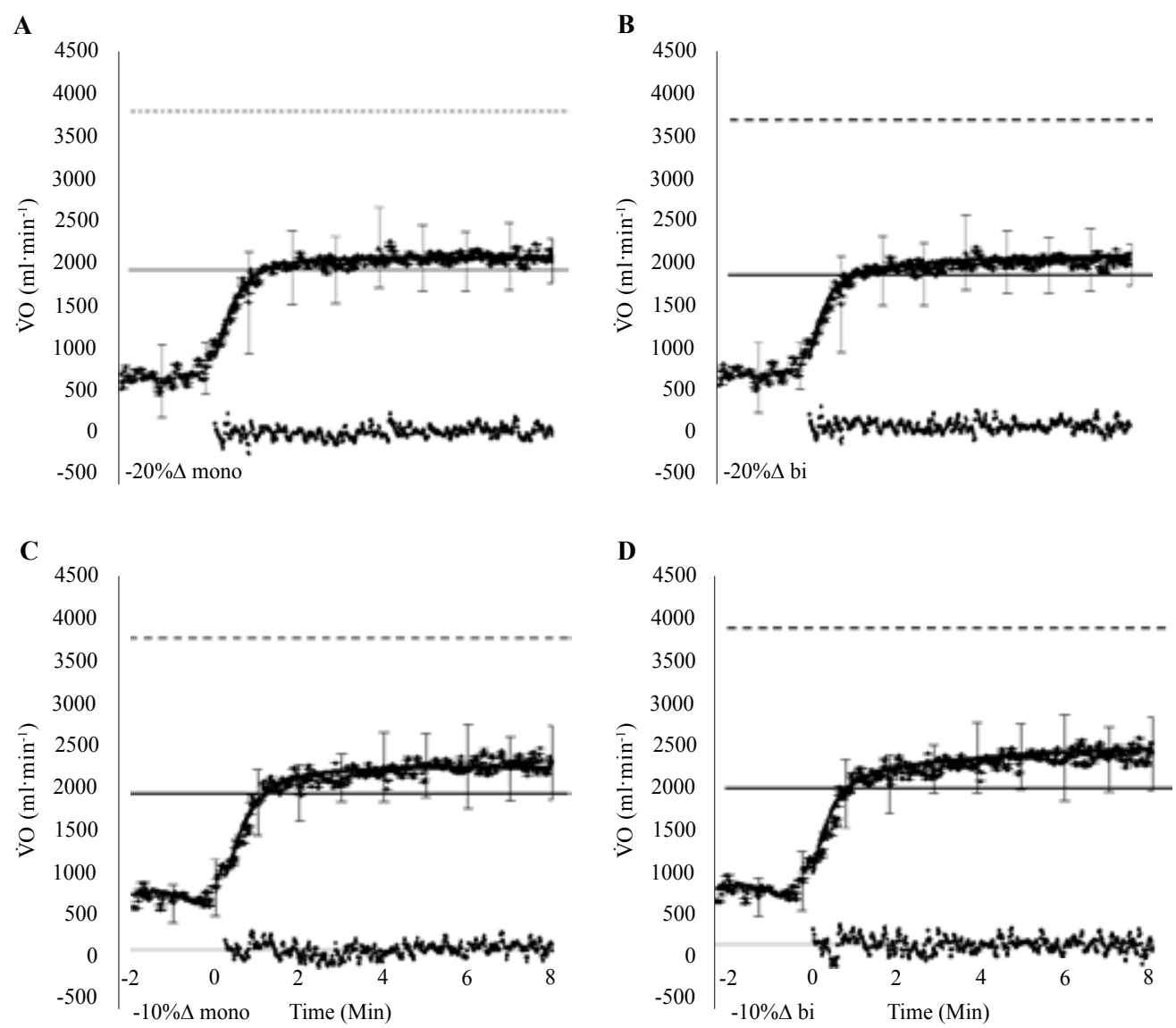

Figure 1. The breath-by-breath oxygen uptake response, mono and bi exponential model fits and residuals across exercise intensity domains in one typical participant. Data from the exercise performed at $-20 \% \Delta$ and $-10 \% \Delta$ are displayed. The $\dot{\mathrm{VO}}_{2}$ at GET (solid line) and $\dot{\mathrm{VO}}_{2 \text { peak }}$ (dashed line). 

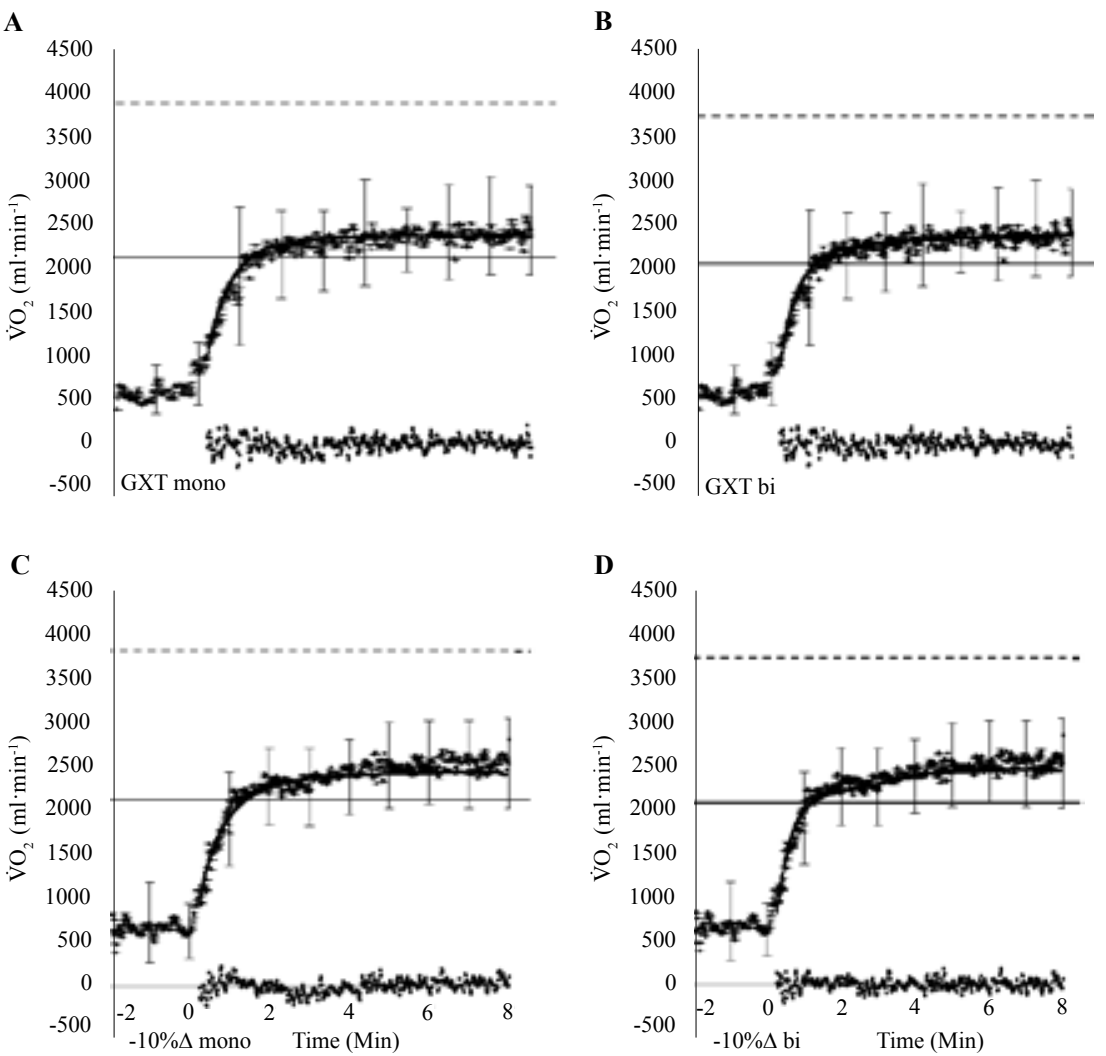

Figure 2. The breath-by-breath oxygen uptake response, mono and bi exponential model fits and residuals across exercise intensity domains in one typical participant. Data from the exercise performed at GET and $+10 \% \Delta$ are displayed. The $\dot{\mathrm{VO}} \mathrm{O}_{2}$ at $\mathrm{GET}$ (solid line) and $\dot{\mathrm{VO}}{ }_{2 \text { peak }}(\mathrm{dashed}$ line).
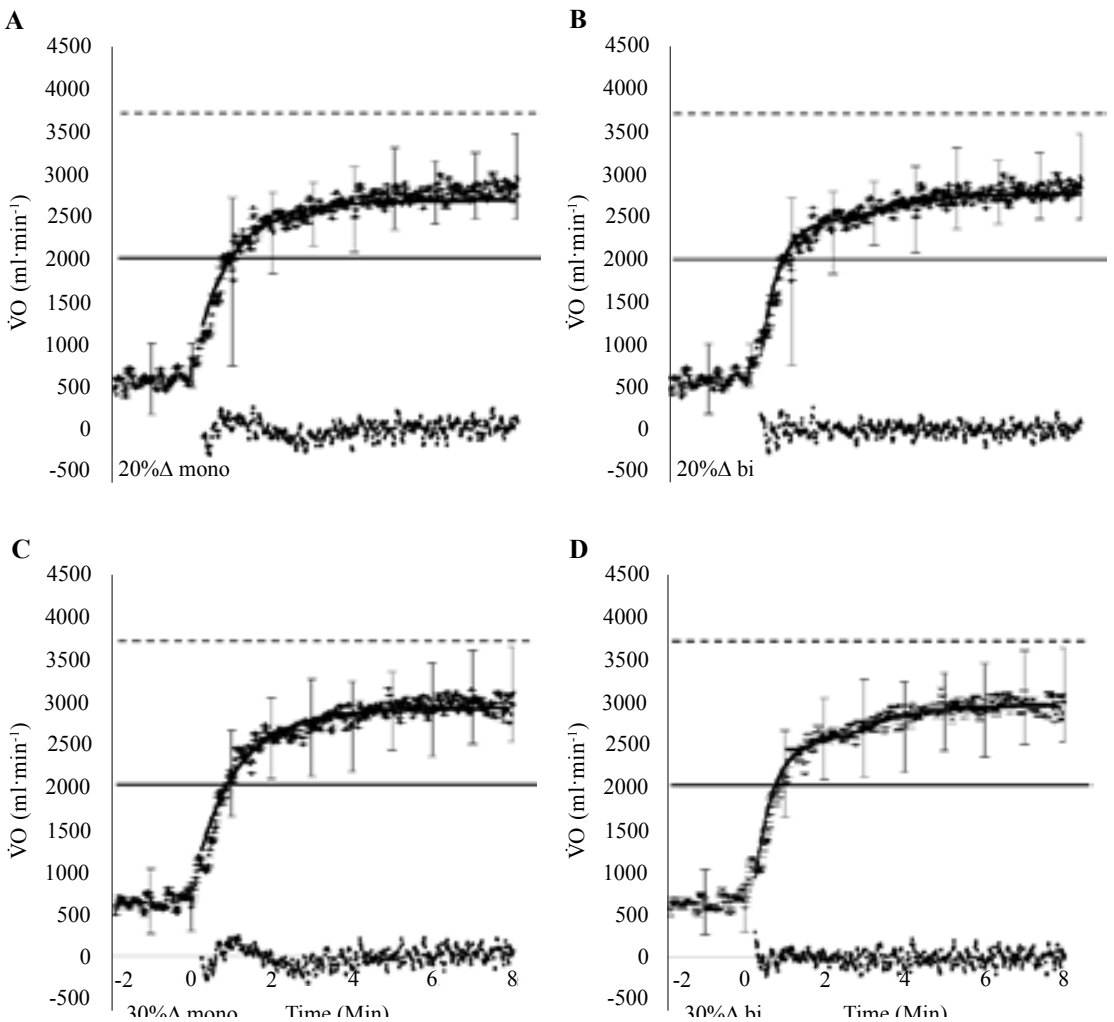

Figure 3. The breath-by-breath oxygen uptake response, mono and bi exponential model fits and residuals across exercise intensity domains in one typical participant. Data from the exercise performed at $+20 \% \Delta$ and $+30 \% \Delta$ are displayed. The $\dot{\mathrm{V}} \mathrm{O}_{2}$ at GET (solid line) and $\dot{\mathrm{V}} \mathrm{O}_{2 \text { peak }}$ (dashed line). 

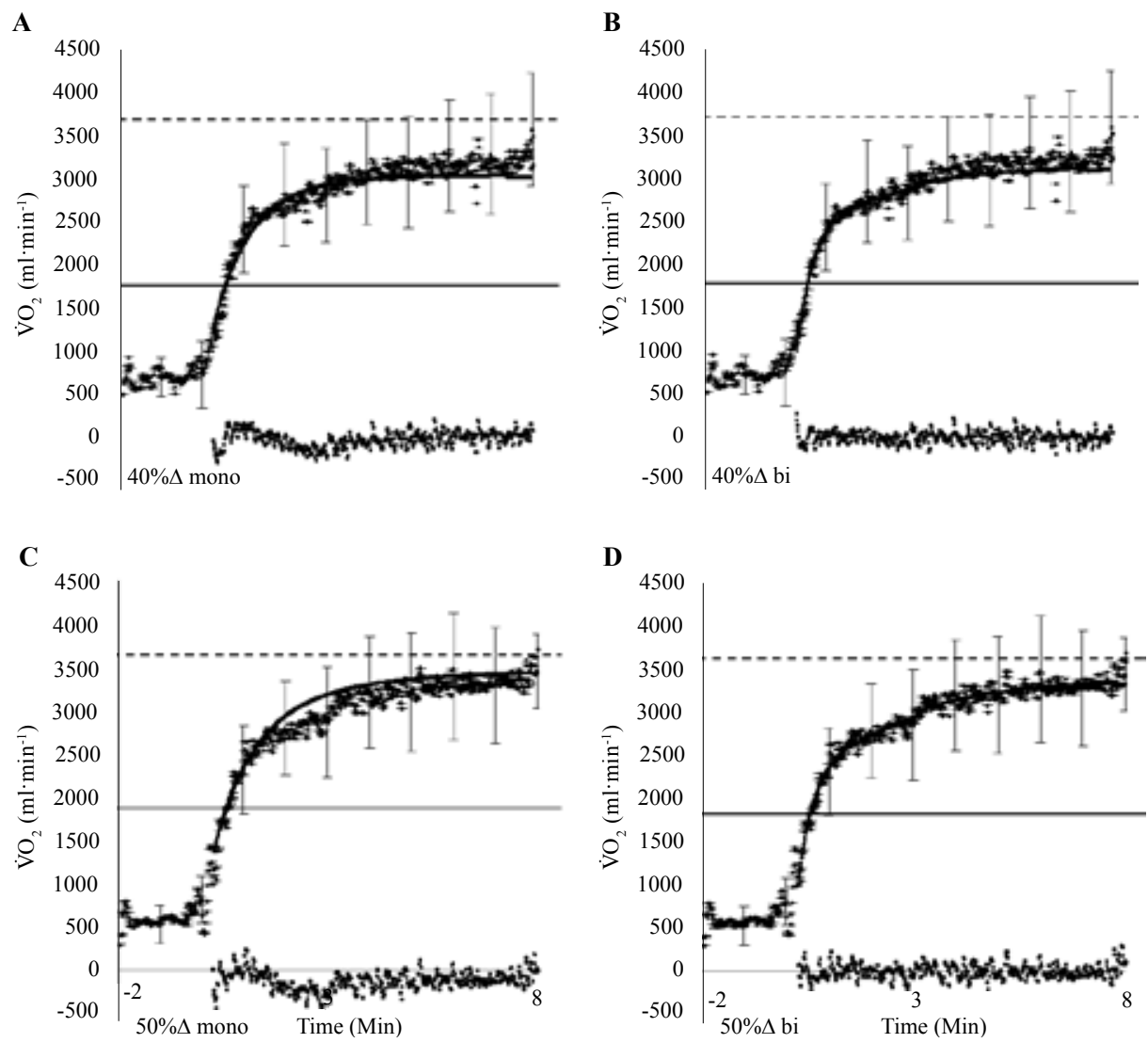

Figure 4. The breath-by-breath oxygen uptake response, mono and bi exponential model fits and residuals across exercise intensity domains in one typical participant. Data from the exercise performed at $+40 \% \Delta$ and $+50 \% \Delta$ are displayed. The $\dot{\mathrm{VO}}_{2}$ at GET (solid line) and $\dot{\mathrm{VO}}_{2 \text { peak }}(\mathrm{dashed}$ line).

\section{Discussion}

The aim of this study was to comprehensively examine $\dot{\mathrm{V}}_{2}$ kinetics during cycling through mathematical modeling of the breath-by-breath gas exchange responses at a range of exercise intensities. In accord with the aforementioned aim, the key findings of this investigation were:

1. Steady-state $\dot{\mathrm{V}}_{2}$ was achieved across all exercise intensities ( $\left(\mathrm{VO}_{2}\right.$ vs. time slopes; $\left.p>0.05\right)$;

2. The bi-exponential model SEE was lower than the mono-exponential model across all exercise intensities $(p<0.05)$, indicating a better model fit, and;

3 . The modelled slow component time constants suggested that the $\dot{\mathrm{V}}_{2}$ kinetic response could not be completed within the duration of the exercise.

\section{Modelling the response}

This present study utilised a mono- and bi-exponential modelling process for all exercise intensities, per literature norms, sub and supra-GET. Despite the convention that has emerged regarding the modelling of $\mathrm{VO}_{2}$ data, i.e. mono-exponential below and bi-exponential above GET, respectively, the SEE was measured in this study comparing the bi-exponential to mono-exponential models. As highlighted in Table 1, the bi exponential model produced SEE values that were significantly lower than the mono exponential model. The standard error of the estimate is a measure of the accuracy of predictions, and in this context, the SEE is a measure of variance between the raw data and the modelled function, so this may be an indication that the bi-exponential model predictions were more accurate than the mono-exponential model. This was evident across exercise intensities, below and above GET. Furthermore, when modelling using the bi-exponential model, a small slow component was also evident below GET (Table. 1).

Although SEE values indicated that the bi-exponential model fit the data better, it should be appreciated that by making a mathematical model more complex (i.e. by adding further parameters), a closer fit to the data will, almost, always be obtained ${ }^{24}$. Motulsky, Ransnas ${ }^{24}$ asserted that comparing two models with the same number of parameters is simple: the fit with the lower sum of squares is superior, for its curve lies closer to the points. Whereas comparing two models with a different number of parameters is appreciably less straightforward because increasing the number of parameters gives more flexibility to the curve-fitting procedure, and almost always leads to a curve that is closer to the points; however, when the number of parameters in a mathematical model is increased, the degrees of freedom are decreased ${ }^{24-26}$. In either case, this presents an issue when deciding if one model is more suitable than another, and is fallacious to assume because one model appears to fit the data 
better, it is the most appropriate choice. The improved fit may be entirely due to the larger number of parameters within the model. A further consideration is the residual plots of the data; where residuals should not be systematically related to the $\mathrm{x}$-axis values and the residual plot will have a random arrangement of positive and negative residuals. However, when residual data appear to cluster, then the equation may be inappropriate or that the data points differ systematically (not just randomly) from the predictions of the curve ${ }^{24}$. Accordingly, visual inspection of the residual plots (Figures 1-4) indicated a clustering of data points when using the mono-exponential model in exercise intensities above GET.

There are well-established reports of using the bi-exponential model above GET, but no reported empirical data below GET. Furthermore, when the kinetics below the GET are explored, the relative exercise intensity tends to be well below the threshold (i.e. $80 \% \mathrm{GET}$ ), and the occurrence of a slow component below GET is not reported ${ }^{13-19}$. To the authors' knowledge, there have been no attempts made to fit the bi-exponential model below the threshold based on the assumption a mono-exponential function must be applied sub-GET.

It is evident amongst the literature that research groups only tend to use relative exercise intensities either well below and/ or well above GET, and in instances where studies do utilise an exercise intensity close to the threshold; it is universally assumed that the $\dot{\mathrm{VO}} 2$ response should be modelled monoexponentially ${ }^{13-19}$, yet there is a surprising lack of empirical evidence from which this assumption was originally proposed and since accepted ${ }^{13-19}$, with some researchers challenging this development. Concerning which model to use, Perrey ${ }^{27}$ asserted that within a single exercise test, it is not clear that a monoexponential response pattern for moderate exercise intensity is the appropriate model choice. Given the evidence that blood flow adapts with two very distinct mechanisms, the muscle pump and the regulatory feedback, it may not be surprising that availability of $\mathrm{O}_{2}$ as an important regulatory substrate could have a clearly different impact on metabolism at different times in the adaptive process ${ }^{28}$.

Virtually all previous literature that has studied across exercise transitions (sub- and supra-GET) have shown concurrent increases in both (primary and slow) amplitudes ${ }^{13,14,29,30}$. This is as a result of the increasing energy demand resulting in an increased oxygen uptake, with $\dot{\mathrm{V}} \mathrm{O}_{2}$ believed to increase linearly with work rate at $\sim 10 \mathrm{ml} \cdot \mathrm{min}^{-1} \mathrm{~W}^{-1}$ during moderate intensity exercise, whilst increasing to $\sim 13 \mathrm{ml} \cdot \mathrm{min}^{-1} \cdot \mathrm{W}^{-1}$ towards supra-GET exercise; increasing exercise intensity involves an increase in motor unit recruitment, and an augmented metabolic heterogeneity of such recruitment, with the collective increase causing increases in the mass of the contracting muscle ${ }^{11,28,31,32}$. A comparable change in $\dot{\mathrm{V}} \mathrm{O}_{2}$ gain was demonstrated in this research (Table 1).

A mono-exponential function has been widely accepted to model the phase-II $\dot{\mathrm{VO}}_{2}$ kinetics as a first-order linear system ${ }^{33,34}$. However, this belief has come under inquiry, as its basis of predicting phase-II kinetic behaviour has been shown to be inaccurate in some empirical experimentation ${ }^{35-37}$. In addition to the use of a potentially over-simplistic model, which combines numerous contributing responses into a single parameter estimate, which is likely not attributable to distinct physiological systems ${ }^{38}$. Recently, McNulty, Robergs ${ }^{12}$ stated that the $\dot{\mathrm{VO}} 2$ response to exercise transitions to steady state is more complex than a monoexponential function. Asserting that there is still much research to be completed concerning the physiological processes, and appropriate modelling, of the $\dot{\mathrm{VO}}_{2}$ kinetic response to exercise transitions to a steady state. McNulty, Robergs ${ }^{12}$ conclude, and aptly question, how can a mathematical model of $\dot{\mathrm{VO}}_{2}$ kinetics be unquestionably followed, when there is still ongoing debate regarding the underlying physiology itself ${ }^{39-42}$.

\section{Transitions to More Intense Exercise}

Mean slope analysis of $\dot{\mathrm{VO}}_{2}$ vs. time for the final minute of exercise in the present study demonstrated that during exercise performed above GET, $\dot{\mathrm{VO}}_{2}$ did stabilise and reach a steady state (Table 1; Figure $1 \mathrm{~b}-\mathrm{d}$ ), where $\mathrm{VO}_{2}$ did not significantly differ from zero. The characteristics of the on-transient $\dot{\mathrm{VO}}_{2}$ kinetic response to supra-GET exercise is described as more complex than the simple mono-exponential model ${ }^{43}$. A typical $\dot{\mathrm{VO}}_{2}$ and metabolite response to supra-GET intensity exercise has been well established and previous research has recognised that during supra-GET exercise the $\dot{\mathrm{VO}}_{2}$ response becomes appreciably more complex with both time and amplitude nonlinearities of response ${ }^{44}$. However, it was clarified by Whipp ${ }^{44}$ that during transitions to supra-GET exercise intensities $\dot{\mathrm{VO}}_{2}$ will reach a steady state. Therefore, based on previous literature, it would be expected that all exercise intensities used in this study would result in a steady state. Generally, $50 \% \Delta$ is classified as supraGET intensity exercise; however there have been reports of the boundary between the supra-GET and severe exercise intensities being $\sim 40 \% \Delta^{14}$, this was not conclusively demonstrated in the present study. Were a boundary at $40 \% \Delta$ evident, both $\dot{\mathrm{VO}}_{2}$ and [BLa $\left.{ }^{-}\right]$would rise inexorably until fatigue ensued, at which point maximum values of $\dot{\mathrm{V}}_{2}$, would have been attained ${ }^{45}$. Although mean final minute slopes were not significantly different from zero (Table 1; Figure 1b-d), large standard deviations were present and, it would, therefore, be pragmatic for authors to report whether the steady state was attained in subsequent empirical investigations.

One issue with the modelling of the slow component is that, generally, the mathematical modelling process results in constraining the data to fit within a predetermined timeframe i.e. the test duration (typically 6 or 8 minutes; Table 1). Based on the resultant parameter values reported in the present study (Table.1), it was evident that the $\dot{\mathrm{V}} \mathrm{O}_{2}$ response is incomplete (based upon the slow component time constant). After $1 \tau$ has elapsed the response will have attained $63 \%$ of its final value, and after $5 \mathrm{x} \tau$ the response will essentially be complete ${ }^{11}$. Furthermore, reported slow component values for steady-state supra-GET intensity exercise, universally, demonstrate this. The shortest slow component time constant reported in this study was $121 \mathrm{~s}$, meaning that the $\dot{\mathrm{VO}}_{2}$ response would not be complete until $605 \mathrm{~s}$, well beyond the 480 s test duration, whilst the longest was 240 s resulting in a complete $\dot{\mathrm{VO}}_{2}$ response, not before $1200 \mathrm{~s}$. There are numerous cases of this contradiction 
of the exponential modelling process in the literature. Carter, Pringle, Jones, Doust ${ }^{14}$ utilised a 360 -second test protocol, at exercise intensities $20 \% \Delta, 40 \% \Delta, 60 \% \Delta, 80 \% \Delta$ and $100 \% \Delta$ they reported time constants of 221.7, 289.4, 247.1, 255.3 and $224 \mathrm{~s}$, respectively. Based on these reported time constants, the earliest response would be complete is $1108.5 \mathrm{~s}$ (for $20 \% \Delta$ ), well beyond the 360 s test duration. Pringle ${ }^{30}$, similarly, reported at $50 \% \Delta$ and $70 \% \Delta$, time constants were 242.3 and 269.4 s respectively for a 360 s test protocol meaning the $\dot{\mathrm{V}} \mathrm{O}_{2}$ response would not be complete until $1211.5 \mathrm{~s}$ (for $50 \% \Delta$ ) (at the earliest), again, long after test cessation. Burnley ${ }^{46}$ reported slow component time constants of 269.2, 250.3, and 216.6s, all for $50 \% \Delta$ (360s test duration), demonstrating the response would not be complete until 1083s at the earliest. Ingham, Carter, Whyte, Doust ${ }^{17}$ and Ingham, Carter, Whyte, Doust ${ }^{16}$ reported time constants of 242 and $258.6 \mathrm{~s}$, respectively, for $50 \% \Delta$, meaning it would take until the 1210 s had elapsed (at the earliest) for the $\dot{\mathrm{V}} \mathrm{O}_{2}$ response to be complete. The reported time constants in these studies, and across the literature, clearly demonstrate that none of the $\dot{\mathrm{V}} \mathrm{O}_{2}$ responses would be complete within the test duration. Additionally, in all of these studies, no attempt was made to fit a two-component model below threshold.

It has previously been asserted that the use of a predetermined timeframe for estimation of the slow component amplitude is not appropriate ${ }^{47}$. Mathematical modelling whilst the $\mathrm{V}_{2}$ response is incomplete, when the kinetics beyond end-exercise are assumed to follow the pattern of the recorded data, likewise, if a steady state has not been reached, any estimation procedures over a rigid period cannot accurately determine the slow component magnitude ${ }^{47}$. Given the evidence surrounding an incomplete exponential process, in addition to the results of the present study, the ability of the current modelling process to accurately and adequately describe the delayed $\dot{\mathrm{V}} \mathrm{O}_{2}$ response should be strongly questioned.

\section{Practical application}

The slow component is an appreciably important physiological phenomenon, however, demonstrable and fundamental issues in its' modelling may obfuscate our understanding of determinants of exercise tolerance and limitations to, in particular, endurance sports performance. It has been shown that exercise priming may significantly change the metabolic and gas exchange responses to subsequent supra-threshold exercise. An initial performance of heavy-intensity exercise, but not moderate intensity exercise, has been shown to speed overall $\dot{\mathrm{V}} \mathrm{O}_{2}$ kinetics during subsequent heavy intensity exercise ${ }^{48,49}$. Furthermore, longer-term training studies have demonstrated diminution of the $\dot{\mathrm{V}} \mathrm{O}_{2}$ slow component with training ${ }^{50,51}$. It is evident that studying the slow component of $\dot{V}_{2}$ further is important for its application to an applied setting. For higher exercise intensities (i.e. above critical power), steady states' in blood acid-base status and pulmonary gas exchange are not attainable, and $\dot{\mathrm{VO}}_{2}$ will increase with time until $\dot{\mathrm{VO}}_{2 \max }$ is reached. It is the interaction of the $\dot{\mathrm{V}} \mathrm{O}_{2}$ slow component, $\mathrm{VO}_{2 \max }$, and the anaerobic capacity that is believed to determine the exercise tolerance ${ }^{50}$. It has been noted that an appreciation of the various exercise intensity domains and their characteristic effects on $\dot{\mathrm{V}} \mathrm{O}_{2}$ dynamics could be helpful in improving our understanding of the determinants of exercise tolerance and the limitations to endurance (and other) sports performance. This suggests that more needs to be known about its appearance and, furthermore, the most appropriate method of determination through modelling.

\section{Limitations}

The present study used cycling as the exercise modality to comprehensively describe the relationship between exercise intensity and the slow component of $\dot{\mathrm{V}} \mathrm{O}_{2}$. Carter, Jones, Barstow, Burnley, Williams, Doust ${ }^{13}$ demonstrated that the $\dot{\mathrm{V}}_{2}$ kinetics were similar for running and cycling, with the exception of the primary (higher in running) and slow component amplitudes (lower in running). Notwithstanding, there is a need to evaluate the effect of the differences in the modelling of the $\dot{\mathrm{V}} \mathrm{O}_{2}$ kinetic response in different exercise modalities. Whilst threshold-based demarcations are limited, this study attempted to ameliorate this limitation by including blood lactate measures pre- and postexercise, so that GET values could be corroborated. A further limitation that must be considered is the incorporation of a single square-wave transition, which therefore necessitates that this work is corroborated across multiple, repeated and extended square-wave transitions.

\section{Conclusion}

1. Whilst the use of best fit has been used as evidence to support two-component modelling, this also demonstrates that a bi-exponential model fit is better, even when a mono-exponential model may be more appropriate.

2. Steady-state $\dot{\mathrm{V}} \mathrm{O}_{2}$ was achieved across all exercise intensities; yet, paradoxically, modelled slow component time constants suggested that the $\dot{\mathrm{V}}_{2}$ kinetic response could not be completed within the duration of the exercise; questioning the appropriateness of the bi-exponential model.

\section{References}

1. Hughson RL. Exploring cardiorespiratory control mechanism through gas exchange dynamics. Med Sci Sports Exerc. 1990;22(1):72-79.

2. Hughson RL, Morrissey M. Delayed kinetics of respiratory gas exchange in the transition from prior exercise. J Appl Physiol. 1982;52(4):921-929.

3. Whipp BJ, Ward SA, Lamarra N, Davis JA, Wasserman K. Parameters of ventilatory and gas exchange dynamics during exercise. J Appl Physiol Respir Environ Exerc Physiol. 1982;52(6):1506-1513. 
4. Whipp BJ, Ward SA. Physiological Determinants of Pulmonary Gas-Exchange Kinetics during Exercise. Med Sci Sports Exerc. 1990;22(1):62-71.

5. Barstow TJ. Characterization of VO2 kinetics during heavy exercise. Med Sci Sports Exerc. 1994;26(11):1327-1334.

6. Beaver WL, Wasserman K, Whipp BJ. A New Method for Detecting Anaerobic Threshold by Gas-Exchange. J. Appl. Physiol. 1986;60(6):2020-2027.

7. Gaskill SE, Ruby BC, Walker AJ, Sanchez OA, Serfass RC, Leon AS. Validity and reliability of combining three methods to determine ventilatory threshold. Med Sci Sports Exerc. 2001;33(11):1841-1848.

8. Casaburi R, Barstow TJ, Robinson T, Wasserman K. Influence of work rate on ventilatory and gas exchange kinetics. J. Appl. Physiol. 1989;67(2):547-555.

9. Poole DC, Barstow TJ, Gaesser GA, Willis WT, Whipp BJ. VO2 slow component: physiological and functional significance. Med Sci Sports Exerc. 1994;26(11):1354-1358.

10. Barstow TJ, Mole PA. Linear and nonlinear characteristics of oxygen uptake kinetics during heavy exercise. J. Appl. Physiol. 1991;71(6):2099-2106.

11. Jones AM, Poole DC. Oxygen uptake kinetics in sport, exercise and medicine. New York: Routledge; 2005.

12. McNulty CR, Robergs RA. New Methods for Processing and Quantifying VO2 Kinetics to Steady State: VO2 Onset Kinetics. Front Physiol. 2017;8:740.

13. Carter H, Jones AM, Barstow TJ, Burnley M, Williams CA, Doust JH. Oxygen uptake kinetics in treadmill running and cycle ergometry: a comparison. J. Appl. Physiol. 2000;89(3):899-907.

14. Carter H, Pringle JS, Jones AM, Doust JH. Oxygen uptake kinetics during treadmill running across exercise intensity domains. Eur J Appl Physiol. 2002;86(4):347-354.

15. do Nascimento PC, de Lucas RD, de Souza KM, de Aguiar RA, Denadai BS, Guglielmo LG. The effect of prior exercise intensity on oxygen uptake kinetics during high-intensity running exercise in trained subjects. Eur J Appl Physiol. 2015;115(1):147-156.

16. Ingham S, Carter H, Whyte G, Doust J. Physiological and Performance Effects of Low- versus Mixed-Intensity Rowing Training. Med Sci Sports Exerc. 2008;40(3):579-584.

17. Ingham SA, Carter H, Whyte GP, Doust JH. Comparison of the oxygen uptake kinetics of club and olympic champion rowers. Med Sci Sports Exerc. 2007;39(5):865-871.

18. Goulding RP, Roche DM, Marwood S. Prior exercise speeds pulmonary oxygen uptake kinetics and increases critical power during supine but not upright cycling. Exp. Physiol. 2017;102(9):1158-1176.

19. Sousa A, Rodriguez FA, Machado L, Vilas-Boas JP, Fernandes RJ. Exercise modality effect on oxygen uptake off-transient kinetics at maximal oxygen uptake intensity. Exp. Physiol. 2015;100(6):719-729.

20. Valdez P, Ramírez C, García A, Talamantes J, Cortez J. Circadian and homeostatic variation in sustained attention. Chronobiol Int. 2010;27(2):393-416.

21. Byers J. Basic algorithms for random sampling and treatment randomization. Comput Biol Med. 1991;21:69-77.

22. Whipp BJ, Ward SA, Wasserman K. Respiratory markers of the anaerobic threshold. Advances in cardiology. 1986;35:47-64.

23. Lamarra N, Whipp BJ, Ward SA, Wasserman K. Effect of interbreath fluctuations on characterizing exercise gas exchange kinetics. J Appl Physiol. 1987;62(5):2003-2012.
24. Motulsky H, Ransnas L. Fitting curves to data using nonlinear regression: a practical and nonmathematical review. FASEB J. 1987;1:365-374.

25. Marquardt DW. An Algorithm for Least-Squares Estimation of Nonlinear Parameters. SIAM J Appl Math. 1963;11(2):431-441.

26. Ratkowsky D. Nonlinear regression modelling: a unified and practical approach. New York: Marcel Dekker; 1983.

27. Perrey S. Comments on point: counterpoint: the kinetics of oxygen uptake during muscular exercise do/do not manifest time-delayed phase. On the physiological issue of td determination with empirical modeling. J Appl Physiol. 2009;107(5):1672-1673.

28. Tschakovsky ME, Hughson RL. Interaction of factors determining oxygen uptake at the onset of exercise. J Appl Physiol. 1999;86(4):1101-1113.

29. Wilkerson DP, Koppo K, Barstow TJ, Jones AM. Effect of work rate on the functional 'gain' of Phase II pulmonary $\mathrm{O} 2$ uptake response to exercise. Respir Physiol Neurobiol. 2004;142(2-3):211-223.

30. Pringle JS. The oxygen uptake slow component in human locomotion. United Kingdom, Manchester Metropolitan University; 2002.

31. Whipp BJ, Wasserman K. Oxygen uptake kinetics for various intensities of constant-load work. J Appl Physiol. 1972;33(3):351-356.

32. Pearce DH, Milhorn HT, Jr. Dynamic and steady-state respiratory responses to bicycle exercise. Journal of applied physiology: respiratory, environmental and exercise physiology. 1977;42(6):959-967.

33. Whipp BJ. Rate constant for the kinetics of oxygen uptake during light exercise. J Appl Physiol. 1971;30(2):261-263.

34. Linnarsson D. Dynamics of pulmonary gas exchange and heart rate changes at start and end of exercise. Acta Physiol Scand Suppl. 1974;415:1-68

35. Brittain CJ, Rossiter HB, Kowalchuk JM, Whipp BJ. Effect of prior metabolic rate on the kinetics of oxygen uptake during moderate-intensity exercise. Eur J Appl Physiol. 2001;86(2):125-134.

36. Koppo K, Bouckaert J, Jones AM. Effects of training status and exercise intensity on phase II VO2 kinetics. Med Sci Sports Exerc. 2004;36(2):225-232.

37. McNulty CR, Robergs RA, Morris D. Influence of increment magnitude and exercise intensity on VO2 kinetics, time to steady state, and muscle oxygenation. J Exerc Physiol Online. 2015; 18:37-58.

38. Bakker HK, Struikenkamp RS, De Vries GA. Dynamics of ventilation, heart rate, and gas exchange: sinusoidal and impulse work loads in man. J Appl Physiol Respir Environ Exerc Physiol. 1980;48(2):289-301.

39. Stirling JR, Zakynthinaki MS, Saltin B. A model of oxygen uptake kinetics in response to exercise: including a means of calculating oxygen demand/deficit/debt. Bull Math Biol. 2005;67(5):989-1015.

40. Stirling JR, Zakynthinaki MS, Billat V. Modeling and analysis of the effect of training on V O2 kinetics and anaerobic capacity. Bull Math Biol. 2008;70(5):1348-1370.

41. Stirling JR, Zakynthinaki M. Last word on point:counterpoint: the kinetics of oxygen uptake during muscular exercise do/do not manifest time-delayed phases. J Appl Physiol. 2009;107(5):1676.

42. Stirling JR, Zakynthinaki M. Counterpoint: the kinetics of oxygen uptake during muscular exercise do not manifest time-delayed phases. J Appl Physiol. 2009;107(5):1665-1667; discussion $1667-1668$

43. Linnarsson D. Dynamics of pulmonary gas exchange and heart rate changes at start and end of exercise. Acta Physiol Scand. 1974;S415:1-68. 
44. Whipp BJ. The slow component of $\mathrm{O} 2$ uptake kinetics during heavy exercise. Med Sci Sports Exerc. 1994;26(11):1319-1326.

45. Gaesser GA, Poole DC. The slow component of oxygen uptake kinetics in humans. EXERC SPORT SCI REV. 1996;24:35-71.

46. Burnley M. Effects of prior exercise on the on-transient oxygen uptake kinetics of constant-load exercise. United Kingdom, University of Brighton; 2002.

47. Bearden SE, Moffatt RJ. VO(2) slow component: to model or not to model? Med Sci Sports Exerc. 2001;33(4):677-680.

48. Gerbino A, Ward SA, Whipp, BJ. Effects of prior exercise on pulmonary gas-exchange kinetics during high-intensity exercise in humans. J Appl Physiol. 1996;80:99-107.

49. Burnley M, Jones AM, Carter H, Doust, JH. Effects of prior heavy exercise on phase II pulmonary oxygen uptake kinetics during heavy exercise. J Appl Physiol. 2000;89:1387-1396.

50. Burnley M, Jones AM. Oxygen uptake kinetics as a determinant of sports performance. Eur J Sport Sci. 2007;7:63-79.

51. Krustrup P, Christensen J, Randers M, Pederson H, Sundstrup, E, Jakobson, M, Krustrup, B, Nielson, J, Suetta, C, Nybo, L, Bangsbo, J.
Muscle adaptations and performance enhancements of soccer training for untrained men. Eur J Appl Physiol. 2010;108(6): 1247-1258.

\section{Corresponding author}

Dr. Cain C. T. Clark

Faculty of Health and Life Sciences, Coventry University, Coventry, CV1 5FB, UK.

Email: cain_1234@hotmail.co.uk

Manuscript received on July 11, 2018

Manuscript accepted on October 18, 2018

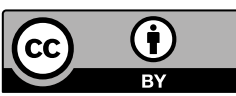

Motriz. The Journal of Physical Education. UNESP. Rio Claro, SP, Brazil - eISSN: 1980-6574 - under a license Creative Commons - Version 4.0 